\title{
Sexo y anonimato. Notas sobre los participantes en encuentros sexuales entre hombres en espacios públicos
}

\section{Sex and Anonymity. Notes about Participation in Sexual Encounters between Men in Public Spaces}

\author{
Jose Antonio Langarita Adiego \\ Facultad de Educación y Psicología. Universitat de Girona
}

\section{RESUMEN}

En este artículo se analizan las relaciones entre clase social, raza, edad, identidad sexual y deseo entre los hombres que practican cruising, es decir, que mantienen relaciones sexuales anónimas con otros hombres en espacios públicos. Para la obtención de los datos que se presentan en esta investigación se ha llevado a cabo un trabajo de campo basado en el método cualitativo y en el que la observación participante y la entrevista han sido las dos técnicas básicas de acceso a la información. Este trabajo demuestra que la llamada comunidad gay es una construcción social que reproduce, en buena medida, los sistemas de estratificación de nuestra sociedad. Pero además, permite analizar cómo se estructura la relación entre los participantes en función del territorio en el que se desarrolla la actividad, de la clase social a la que pertenecen y de su origen. Así mismo, se abordan los conflictos derivados de una identidad heterosexual y una práctica homosexual en las zonas de cruising.

Palabras clave: Sexo anónimo, Homosexualidad, Homofobia, Teoría LGTBQ, Estratificación social.

\section{SUMMARY}

In this paper analyses the relationship between social class, race, age, sexual identity and desire among men who practice cruising, the act of anonymous sexual relationships with other men in public space. The basic techniques used to obtain the data for analysis were through the qualitative methods of participant observation and interviews. This work show that the so-called gay community is a social construction that largely reproduces the stratification systems of society. In addition, it allows an analysis on how the the relationship among participants is structured according to the territory which it operates, the social class of the participants and their origin. Furthermore, it covers the identity conflicts originated from the heterosexual identity and homosexual practice in cruising areas.

Key words: Anonymous Sex, Homosexuality, Homophobia, GLTBQ Theory, Social Stratification. 


\section{INTRODUCCIÓN}

Este trabajo de investigación se presenta como el resultado de un análisis cualitativo del intercambio sexual anónimo en el que la observación participante y la entrevista han sido las técnicas fundamentales para la obtención de la información. Las zonas de cruising se caracterizan por una forma de comunicación particular en la que los participantes interactúan sin el uso de la palabra, de manera que la negociación y acceso al sexo se realiza en silencio. Este hecho ha provocado que las entrevistas con mis informantes se hayan visto notablemente afectadas y, aunque he podido realizarlas, la observación participante ha sido la técnica que mejor me ha permitido conocer el funcionamiento de este tipo de escenarios. El acceso al campo se llevó a cabo a partir de múltiples visitas exploratorias y de observación en las que pude sumarme a las negociaciones y prácticas sexuales que se daban en las zonas de cruising. En este sentido, el hecho de que yo también haya sido construido como hombre homosexual ha facilitado indiscutiblemente el acercamiento a las zonas de cruising en la medida en que me ha permitido ser objeto de deseo y deseante respecto a los otros participantes. El contacto con los practicantes se ha realizado respetando los canales de interacción que regulan las zonas de cruising, es decir, a través de un acercamiento en silencio y cargando la mayor parte del ejercicio comunicativo en la expresión corporal. Una vez iniciada la relación a través del lenguaje corporal, buscaba la oportunidad de interactuar verbalmente para ampliar la información que se producía en el cuerpo a cuerpo. En algunas ocasiones la interacción verbal se reducía a frases cortas, aunque cargadas de significado, y en otras podía iniciar una conversación que permitía ampliar los datos recogidos mediante la observación participante. En el caso de las entrevistas en profundidad, el acercamiento a los informantes se realizó a través de los contactos personales que se prestaron a colaborar con esta investigación o de asociaciones vinculadas al ámbito de la diversidad sexual.

El objetivo principal de esta propuesta es defender que el hecho homosexual debe analizarse en relación al contexto económico, social y cultural en el que se desarro1la. En este sentido pretendo abordar los posibles criterios de clase que se reproducen en la práctica del cruising, discutir la cuestión de origen y edad como condicionante del acceso al sexo, profundizar en la producción de la identidad en las zonas de cruising y mostrar algunas de las perspectivas de los participantes con respecto con las relaciones sexo-afectivas dentro y fuera de las zonas de cruising.

Esta investigación se ha desarrollado en tres escenarios diferentes de intercambio sexual anónimo: el Parque de Montjuïc (Barcelona), la playa de Gavà y Sitges (bosque y playa). No obstante, también se han realizado visitas exploratorias a otros lugares, como la zona de cruising de la playa Mar Bella de Barcelona o algunos lavabos públicos de Barcelona. El hecho de que la expansión territorial del objeto de estudio se limite únicamente a algunas de las zonas de cruising de la provincia de Barcelona podría ser considerado como una reducción que obstaculiza el alcance del análisis. En efecto, una comparación con diferentes contextos culturales hubiese sido interesante para ahondar en otras posibilidades de interpretación. Pero no por tratarse de una investigación acotada en un ámbito territorial como el que se propone carece de revelaciones que puedan contribuir a la construcción de una teoría social de la sexualidad. Me pregunto si existen más diferencias entre Barcelona, Berlín o Londres, 
por ejemplo, que entre Barcelona, Gavà y Sitges. Un análisis territorialmente reducido no necesariamente limita las posibilidades de estudio, sino que por el contrario puede ofrecer algunas claves que contribuyan a entender la organización social del sexo a partir de unos parámetros de proximidad.

La práctica del intercambio sexual anónimo entre hombres en espacios públicos se conoce popularmente entre la población homosexual con el nombre de cruising. Sin embargo, su significado no se reduce únicamente al acto sexual en sí mismo, sino que también acoge el conjunto de normas de comportamiento que regulan la interacción y conducen a los participantes al contacto sexual. En esta línea, Michael Reece y Brian Dodge definen esta actividad como "el ritual de búsqueda e interacción de potenciales parejas sexuales que, normalmente, no se conocen previamente» (Reece y Dodge 2004: 112).

Aunque la práctica del cruising sea una actividad fundamentalmente anónima, no podemos dejar de preguntarnos acerca de quiénes son las personas que frecuentan este tipo de espacios. Pero más interesante que tratar de identificar a unos sujetos que no se quieren identificar, es abordar la cuestión de identidad, clase, raza y deseo a partir de la mirada que nos proporciona esta actividad. Por ello, a lo largo de este artículo no trataré de construir biografías ni tipologías de usuarios, sino que más bien realizaré un análisis de circunstancias. El interés de estudiar a los hombres que participan en la actividad del cruising no es presentar un sujeto completo y coherente, sino estudiar algunos de sus aspectos que puedan servir de punto de partida para interpretar la realidad social.

En una primera instancia, la respuesta a la pregunta sobre quiénes son los participantes de las zonas de cruising podría ser simple: - hay todo tipo de personas-, de hecho esta es la respuesta de la mayor parte de usuarios cuando se les pregunta por este asunto. Sin embargo, de este modo, lo único que haríamos sería reproducir el mito de que la homosexualidad ha superado las cuestiones de clase y raza a causa de la experiencia común de la homofobia.

Laud Humphreys, pionero en el estudio sobre el sexo anónimo, se mostraba fascinado por la diversidad de población que acostumbra a frecuentar este tipo de lugares: "en estas zonas de intercambio sexual existe una especie de democracia endémica de sexo impersonal. Hombres de todas las razas, clases sociales, educación y diferentes características físicas se reúnen por estos lugares y son unidos por el sexo" (Humphreys 1975: 13). No obstante, y más allá de las críticas al trabajo de Humphreys (ver Schacht 2004), debemos contextualizar su investigación en los años 70 del siglo $\mathrm{XX}$, cuando la pandemia del VIH todavía no había hecho estragos entre la población gay, y los movimientos de liberación sexual comenzaban a expandirse tras las revueltas de Stonewall (Duberman 1994). Es indiscutible que entre el contexto social norteamericano en el momento en que Humphreys escribió su monografía y el actual hay una gran diferencia que hace que cualquier comparación deba tener en cuenta estas cuestiones diacrónicas, territoriales, políticas y sociales. Es por ello por lo que la idea de "democracia endémica" en las zonas de cruising no puede ser trasladada al contexto actual y puede ser discutida. Veamos el porqué. 


\section{SEXO Y TERRITORIO}

Si se insiste en la pregunta de quiénes son estas personas que hacen cruising, en esta ocasión debería de responder: —Depende-. Depende especialmente del lugar y de la hora, e incluso de la estación del año. Podría generalizar y decir que las personas que van a la zona de cruising de Sitges son fundamentalmente turistas en verano, pero que se relacionan en algunas ocasiones con otros hombres de la comarca. En el caso de Gavà, se trataría de un grupo de hombres de una edad superior a los treinta y cinco años, del área metropolitana de Barcelona, y un buen número de ellos casados con mujeres y que mantienen oculto a su red social y familiar su deseo de tener prácticas sexuales con otros hombres.

Si me tuviera que referir al parque de Montjuï, diría que el tipo de población que acostumbra a frecuentar la zona de cruising es muy variado, pero sin embargo, no es habitual ver turistas buscando sexo, tal y como sucede en Sitges, y tampoco muchos chicos jóvenes, aunque los hay. Más que nada, y otra vez generalizando, diría que es un grupo de población que normalmente se encuentra entre las capas más bajas de la escala de legitimidad social: inmigrantes y personas mayores, normalmente.

Pero a pesar de este intento de explicar algunas características básicas de los participantes de las zonas de cruising, nuevamente me encuentro sin cumplir mi propósito de defender la idea de que el análisis de las zonas de cruising puede servir para entender los sesgos de clase, raza y capitales personales que envuelven la población homosexual. Sin embargo, sí que se puede confirmar una primera diferencia social en torno al territorio y la práctica del sexo anónimo, es decir, los entornos en los que se encuentran las zonas de cruising determinan en gran medida el tipo de población que asiste a ellas. De tal manera que Sitges, por ejemplo, uno de los pueblos con mayor turismo homosexual del Estado Español, así como un lugar con gran prestigio social, cuenta con un grupo de participantes en las zonas de cruising que, a excepción de los habitantes de la comarca, se dirigen al espacio de intercambio sexual después de una jornada lúdica y vacacional. La práctica sexual con otros hombres es precisamente una de las motivaciones de las vacaciones de muchos de los visitantes. Los turistas que frecuentan la zona de cruising en Sitges, normalmente, no tienen impedimento alguno en mostrarse como homosexuales por las calles del pueblo y, además, cuentan con una amplia red de establecimientos y locales para satisfacer sus necesidades de ocio y descanso.

Por su parte, el parque de Montjuïc se encuentra cercano al barrio de Poble Sec y también al del Raval, históricamente ligados a población fuertemente estigmatizada como es el caso de prostitutas, ladronzuelos, consumidores de drogas, homosexuales y recién llegados a la ciudad. La zona de cruising de Montjuïc ha sido uno de los lugares más conocidos para el intercambio sexual entre hombres de Barcelona. No obstante, la aparición de nuevos escenarios, como discotecas, bares y saunas, así como la expansión del uso de las nuevas tecnologías para fomentar los contactos sexuales ha hecho que esta zona de cruising haya quedado relegada, en gran medida, a aquellas personas de los barrios cercanos y con dificultades de acceso a los otros recursos sexuales. Es decir, de alguna manera, se ha convertido en el lugar de gozo sexual para aquellos hombres que no pueden colgar su foto en un perfil de internet por miedo a ser reconocido como homosexual; de los que están casados; para quienes 
su descubrimiento podría ser catastrófico en su contexto social más próximo; para los que tienen dificultades para salir del armario y contradicciones con sus patrones culturales y morales, o incluso para quienes no disponen de los recursos económicos suficientes para pagar la entrada y consumición en discotecas para gais. Esta transformación en el tipo población que frecuenta el parque ha sido relatada por diversos informantes:

Antes en Montjuïc había todo tipo de personas, cuando llegué a Barcelona había de todo, pero ahora la gente joven liga por internet y ya no va allí. Ahora todos son señores mayores de más de 40 años. A mí me gusta la gente más joven que yo, de veinte hasta treinta, y la gente de más de cuarenta no me atrae nada, por eso dejé de ir a Montjuïc. (Jean, 48 años, originario de Bélgica pero residente en Barcelona desde hace más de 15 años) $)^{1}$.

Los homosexuales que tienen recursos económicos y un capital cultural que les permite vivir una vida homosexual abierta o semi-abierta han dejado de considerar el parque de Montjuïc como un espacio legítimo para la práctica y la interacción sexual, no solo porque existen alternativas sexuales en otros escenarios, sino también porque el estatus social de las personas que frecuentan hoy la zona de cruising ya no les resulta atractivo. Esto podría llevarnos a pensar que, para un buen número de gais, lo que hace "denigrante" la zona de cruising de Montjuïc no son tanto los ejercicios de promiscuidad, que también se llevan a cabo en saunas y cuartos oscuros de discotecas, sino el tipo de población que merodea por allí. Uno de los asistentes a la zona de cruising de Gavà se refería al parque de Montjuïc diciendo que:

Yo hace muchos años que ya no voy. Porque lo que hay ahora, pues es mucho marroquí, y a ver, no soy racista. Pero no me fío. Porque ya te digo, es un intercambio de tú me haces esto, yo te hago esto, y me tienes que dar algo a cambio. Los marroquíes siempre piden algo a cambio (Julián, 64 años, hombre del sur de España pero residente en Cataluña, casado con otro hombre con el que mantiene una relación abierta).

Las personas que hacen cruising en el parque de Montjuïc no son las mismas que frecuentan los bares, restaurantes y discotecas para gais de la ciudad. Otro de los participantes aseguraba:

Suelen ir gente casada, gente que no está fuera del armario. Luego también hay un grupo de gente que es sexualmente bastante activa y gente mayor, también suele ir bastante. Lo que veo es gente que no te encuentras luego en el ambiente ni en los chats. Se trata de gente que solo va allí, y que en su vida cotidiana no son gais abiertos (Albert, 32 años, nacido en Cataluña y residente en la comarca del Garraf).

De las informaciones que ofrecen algunos entrevistados, así como de mis propias observaciones, se deduce que a las zonas de cruising no son frecuentadas por todo tipo de homosexuales. Es decir, los turistas que van a la zona de cruising de Sitges lo hacen con la expectativa de ligar con personas de su misma condición social: la de turista, occidental y con cierto poder adquisitivo. De la misma manera, los chicos que dejan de frecuentar la zona de ligue del parque de Montjuïc lo hacen porque

\footnotetext{
${ }^{1}$ Todos los nombres de participantes que aparecen en este artículo han sido modificados para preservar el anonimato de los informantes.
} 
allí ya no se encuentran personas con el estatus social al que ellos pertenecen o creen pertenecer: jóvenes, de origen nacional, con un cierto grado de formación, etc. De manera que ese anonimato que se presupone en las zonas de cruising es un anonimato relativo, ya que, al fin y al cabo, en cada lugar existe un grupo de población participante con algunas particularidades sociales que determinan la medida en la que se convierte en un espacio de legitimidad sexual para los sujetos que deciden participar en él. Los usuarios se dirigen a las zonas de cruising para encontrar a otros hombres que le resulten conocidos, aunque ignoren sus nombres. Los turistas que van a la zona de cruising de Sitges, lo hacen para follar ${ }^{2}$ con los suyos, con los que les son familiares, con los que les son conocidos en tanto que comparten patrones económicos, culturales y sociales. En este sentido, Manuel Delgado asegura que a pesar de que puedan existir territorios sin identidad no puede haber cuerpos sin identificar, sin esclarecer, porque pensar es pensar socialmente y esto comporta, inevitablemente, también, clasificar socialmente (Delgado 2011: 70).

\section{CUESTIÓN DE CLASE}

Las relaciones de clase también determinan los comportamientos sexuales (Lauman et al. 1994: 4; Green 2008). Sin embargo, hasta hace relativamente poco tiempo, ni los estudios sobre sexualidad han tenido en cuenta la cuestión de clase, ni los que se preocupan por los asuntos de la clase social han tomado en consideración la cuestión sexual como un elemento importante para interpretar la realidad social (Binnie 2011; Fraser 1999; Taylor 2011). La sexualidad se ha considerado generalmente como un elemento que pertenece al ámbito de lo íntimo, como si se tratase de un hecho que se produce al margen de las relaciones económicas, sociales y culturales, cuando en realidad el sexo es, sobre todo, un hecho social.

Aunque los nexos entre identidad sexual y capitalismo sean complejos, no existe ningún indicador que niegue este vínculo (Hennessy 2000). La relación entre sistema económico e identidad sexual se ve constatada en diferentes momentos de la vida social. La constitución de la homosexualidad como nicho de mercado establece una diferencia de carácter económico que hace visible las grandes desigualdades que se generan dentro de la "comunidad homosexual". De la misma manera que la sociedad capitalista en la era post-industria ha llevado a la clase trabajadora a la individualización a partir del consumo (Bauman 2003; Beck 2006; Castel 1997), las vidas homosexuales también se han construido en términos individuales respecto a la elección de un consumo fragmentado. La comunidad homosexual ha resuelto la cuestión de la desigualdad social generada por su objeto de deseo a partir de la ficción de la igualdad de oportunidades del capitalismo post-industrial, como si liberación y consumo fuesen dos términos con igual significado, como si todos los homosexuales

\footnotetext{
${ }^{2}$ Con el uso del concepto "follar" pretendo recoger los significados culturales que ofrece la palabra que van más allá de mantener relaciones sexuales. A pesar de que mantener relaciones sexuales y follar en algunas ocasiones puede entenderse como dos nociones de igual significado, el sentido cultural de una y otra es diferente. Mientras que la primera se presenta como neutra y correcta, la segunda tiene una carga significante más lasciva.
} 
estuviesen en igualdad de condiciones sociales, económicas y culturales para poder resolver de manera individual la homofobia generalizada. No cabe duda de que la homofobia es una realidad que afecta en todas las capas sociales, pero no todos los homosexuales están en las mismas condiciones de hacerle frente. Por lo tanto, las respuestas individuales a la homofobia dependen en gran medida de los capitales culturales y económicos de los que dispone el sujeto. Con esta afirmación no desearía que se pensase que los sujetos homosexuales se han convertido en personas que solo atienden a necesidades privadas e individuales. Lo que intento es problematizar la relación entre capitalismo y homosexualidad hasta convertirse en la única vía de acceso a los referentes gais para un buen número de hombres que no encuentran otros relatos alternativos al consumo.

Evidentemente, la desigualdad no puede reducirse a aspectos económicos, pero sería un desacierto creer que la realidad homosexual se ve exclusivamente afectada por el determinismo cultural de la homofobia sin tener en cuenta la intromisión del capitalismo en la constitución de la identidad sexual (ver Hennessy 2000). Las desigualdades materiales no son elementos sin importancia en la configuración de las identidades sexuales (Heaphy 2011). Si el sistema económico y social occidental se rige fundamentalmente por patrones capitalistas, y si la población gay ya cuenta con un amplio mercado de consumo en expansión, ¿qué nos puede hacer pensar que entre los gais no se responde a los parámetros de exclusión que dispone el capitalismo? Brian Heaphy apunta que los argumentos que hacen visibles las sexualidades tienen un fuerte componente de mercantilización y que, por lo tanto, la visibilidad gay está concebida solo para un grupo socio-económico privilegiado (ibid.: 44 -45). ¿Qué les queda a los otros, a los que no tienen acceso a estos recursos económicos? Les quedan los lavabos, los parques, las playas y otros escenarios de acceso a la sexualidad que tienen un bajo coste en el mercado.

A estas alturas, ya nos encontramos en condiciones de entender por qué en Montjuïc una buena parte de los participantes son marroquíes, paquistaníes, bengalíes, de Europa del Este o de África subsahariana; por qué abundan los viejos; por qué algunos "apestan a alcohol". Podemos entender por qué, a pesar de que también hay españoles y catalanes, muchos de estos justifican su presencia alegando estar en el paro. Es decir, al parque de Montjuïc van mayoritariamente a ligar los que no pueden ir a otro sitio.

\section{ORIGEN, EDAD Y ESTÉTICA}

Otro de los elementos característicos de los participantes de la zona de cruising es su diversidad de origen. En el caso de Sitges, los participantes suelen ser franceses, alemanes, británicos, norteamericanos o españoles, en cualquier caso, occidentales en general. Sin embargo, en Montjuï, fundamentalmente se trata de aquellos a los que se les atribuye la categoría "inmigrante" según las clasificaciones que operan en nuestra sociedad. Evidentemente, también el parque es frecuentado por algunos catalanes o españoles residentes en Barcelona o su área metropolitana, pero en un número menos significativo. Prueba de ello son los continuos comentarios que hacen referencia a su amplia presencia en el parque y a la devaluación de la actividad: 
Hoy en día casi todos son de fuera. Marroquís, o de países del Este. Porque viven a salto de mata, tienen necesidad y, como no encuentran trabajo, pues vienen a ver que pillan. Muchos lo hacen porque les gusta, si lo hacen por necesidad pues mira, yo si me encontrara en las mismas circunstancias también lo haría (Julián, 64 años).

Las personas inmigrantes son percibidas, en algunas ocasiones, como personas que restan valor a la zona y son motivo suficiente para dejar de participar en la actividad del sexo anónimo. Compartir un mismo espacio social implica compartir una misma condición y una identidad social degradante (Aramburu 2002), por lo que muchos usuarios se quejan del creciente número de personas inmigrantes en las zonas de cruising. Aunque no todos los usuarios piensan de este modo, el origen de los participantes constituye un nuevo sesgo en la elección de la pareja sexual que los iniciados acostumbran a tener muy presente a la hora de establecer sus relaciones. No es habitual encontrar a personas de origen magrebí, por ejemplo, en interacción con personas del Estado Español. ¿Por qué sucede esto? Una de las explicaciones más convincentes es que los prejuicios preexistentes respecto a la inmigración en la sociedad madre también son trasladados a las zonas de cruising donde se reproducen sin ser cuestionados.

A los inmigrantes se les sigue atribuyendo unas intenciones especiales en las zonas de cruising que están determinadas por su condición de otro. Las explicaciones de su presencia allí se justifican por diferentes motivos. Por ejemplo, que los inmigrantes van a la zona de cruising porque "viven a salto de mata" y no saben organizar su vida sexual. Pero, además, otra de las atribuciones que se asigna a las personas inmigrantes es su condición de sujetos en evolución (Aramburu 2002) que todavía no han alcanzado la aceptación de la diversidad sexual, tal y como ya se ha hecho en Occidente. Como si las personas inmigrantes fuesen a las zonas de cruising únicamente por la contención sexual a la que están sometidos en sus contextos de origen, o por las regulaciones culturales de sus grupos de afinidad en el país receptor.

Otra de las atribuciones sociales a las personas inmigrantes que se traslada a las zonas de cruising es su condición de delincuentes. Uno de los informantes de esta investigación afirmaba: "los marroquíes van a las zonas de cruising para robar, quien va a las zonas de cruising ya lo sabe" (Pau, 39 años, miembro de entidad de defensa de los derechos de la población LGTB), dado que su condición no les permite disponer de otros objetivos en la interacción con los demás que vayan más allá del robo, o en el mejor de los casos, de la recaudación económica. En este sentido este informante continua diciendo que: "quien va a hacer cruising sabe perfectamente quién es chapero y quién no. Tú ves en la zona de cruising a un árabe y casi seguro que es chapero. El árabe no va por intercambio, sino que va a ganarse la vida". La presencia de inmigrantes, especialmente marroquíes, en las zonas de cruising es percibida como interesada económicamente, entendiendo así que los inmigrantes no pueden frecuentar el parque para satisfacer sus deseos sexuales como lo hacen otros participantes. Su figura está repleta de segundas intenciones que siempre son cuestionadas y objeto de duda.

Las personas inmigrantes son acusadas de falta de higiene, que también se relaciona con sus patrones culturales y biológicos. "La negra está muy buena, pero echa 
un olor que no te puedes acercar", aseguraba Toño, un participante de 41 años residente en la comarca del Garraf ${ }^{3}$. En otra ocasión explica:

Ese moro tiene un trancazo así [hace gesto exagerado con las manos]. Pero yo no se la he chupado, he estado dos veces con él, pero al acercarte pega un olor muy fuerte. Es el olor de su piel, igual que la de los negros [...] entras a una discoteca y si hay negros tienes que ponerte la mascarilla (Toño, 41 años).

Los negros y los árabes son admirados por una supuesta grandeza de sus atributos genitales y sus dotes sexuales. Sin embargo, la figura del negro o del marroquí funciona como fetiche imaginario que normalmente, en las zonas de cruising, se queda en la imaginación y raramente traspasa esa frontera para convertirse en realidad. Los prejuicios sobre las personas inmigrantes tienen mayor fuerza que el juego fetichista que representan, y así, a pesar de que los negros estén en muchas de las representaciones sexuales, la relación con inmigrantes solo se establece cuando existe un marco social que garantice que se trata de una relación marcada por el paradigma occidental, es decir, cuando se puede comprobar que, a pesar de ser negros o árabes, disponen de suficientes recursos económicos y comparten el estilo de vida occidental. Aunque los hombres negros sean un fetiche, solo se convierten en pareja sexual cuando su capital económico y cultural les permite hacerse visibles en espacios sociales normalizados para la interacción homosexual.

¿Tú sabes cómo están de buenos? ¿No has follado con ningún negro? Pues no has probado el caviar. Pero hablo de negros americanos limpios, no de los que hay aquí guarrindongos. Los negros huelen diferentes, pero el Kevin (un negro norteamericano) cuando se desnudó olía a rosas y, como olía bien, le follé, le comí el culo y le chupé todo. Me mintió, porque me dijo que era virgen y no era verdad. Los negros son mentirosos. Eso sí que es verdad. Mienten. Les gusta mentir. Pero este tenía un buen culo y una buena polla (Toño, 41 años).

En esta línea es interesante acercarnos a la propuesta de Johnson (2008) que analiza la erotización de los chavs ${ }^{4}$ entre la población gay de Inglaterra. A partir de un brillante análisis, el autor defiende la idea de que, en realidad, la utilización del chav como sujeto homoerótico no deja de ser una representación que no se desea, de la que solo se simbolizan los atributos sexuales, pero que en realidad mantiene el sesgo de clase. Podríamos pensar que, en el caso de la homoerotización de los negros, pasaría algo similar. Se representan como sujetos con excesos sexuales y por ello objeto de deseo pero, sin embargo, este hecho no es suficiente para incorporarlos y establecer relaciones de igualdad con ellos.

${ }^{3}$ La cuestión del olor es significativa también en otro sentido, ya que más allá de los olores corporales, algunos participantes desprenden un fuerte olor a alcohol. El hecho de asistir a las zonas de cruising cuando se está borracho o drogado, puede servir como excusa non compos mentis. Flowers, Hart y Marriot (1999: 489) consideran que el "estaba borracho" puede representar una justificación culturalmente aceptable que absuelve al sujeto de la estigmatización de la actividad que lleva a cabo.

${ }^{4}$ Chavs es la palabra que se utilizar en Inglaterra para hacer referencia a un grupo de jóvenes estereotipado de la clase trabajadora del país. En el caso del Estado Español podríamos hablar de los estereotipos "garrulo" o "poligonero" como un sinónimo, salvando las diferencias culturales, de lo que en Inglaterra se llama chavs. 
A los marroquíes se les asocia con el mundo de la prostitución en las zonas de intercambio sexual anónimo. Sin embargo, ni en el parque de Montjuïc, ni en Gavà ni tampoco en Sitges he podido verificar esta afirmación tan extendida. Bien es cierto que en ocasiones puntuales y de manera sutil pueden darse situaciones en las que tras la interacción sexual también se produce algún intercambio monetario, pero se trataría de un hecho puntual, que no se produce únicamente con los marroquíes, y no es tan generalizado como para resultar significativo ni definitorio del tipo de actividad que llevan a cabo los marroquíes allí.

A pesar de esta percepción del inmigrante como sujeto con unas características con naturaleza propia, es necesario apuntar que la categoría inmigrante es muy heterogénea en lo que respecta a sus formas de expresión cultural (Brettell 2003; Santamaría 2002). A lo largo del texto, me he tomado la licencia de estructurar los criterios de clasificación a partir de los que se proponen en las distintas conversaciones mantenidas con los participantes. Soy consciente de que este lenguaje clasificatorio basado en categorias emic no sería aceptado en otro tipo de presentación, pero en este caso resulta útil para dibujar un mapa de la estratificación social dentro de la zona de cruising. Es por ello por lo que es necesario destacar que no todas las personas inmigrantes están igualmente estigmatizadas, normalmente, las personas de origen latinoamericano tienen un grado de aceptación mayor y sus interacciones sexuales suelen ser mucho más eficaces e inmediatas que las de los paquistaníes o marroquíes cuando se relacionan con personas españolas o catalanas.

Existe otro valor que regula la jerarquía de las oportunidades sexuales. Se trata de la edad. Las personas mayores son percibidas como molestas, y conforman un grupo poco deseable. Uno de los participantes aseguraba:

A mí antes me gustaba mucho el Parque de Glorias, pero iba siempre drogado. ¿Sabes? Cuando iba a Glorias iba drogado. Llegaba puesto en plan, iQuiero follar!, ¿Quiero follar!, ¡Quiero follar! Y a las horas que iba pues me encontraba la mejor fauna que te puedes imaginar [...] y cuando llegaba había siempre viejos, cuatro viejos que no te dejaban en paz, que te perseguían todo el rato, hasta el punto que tenías que decir -ifuera!, ¡Dejadme en paz!- (Carles, 36 años, nacido en Cataluña y residente en Barcelona).

La vejez está relacionada con la pérdida de aceptación de las personas en los espacios comunes (San Román 1990). En el caso de las zonas de cruising, las personas mayores disminuyen notablemente las oportunidades sexuales y hace que muchas de ellas reduzcan su actividad sexual a mirar cómo los otros mantienen relaciones o a interactuar con participantes también devaluados. Por lo tanto, en las zonas de cruising existe lo que podemos llamar cadena de estigmatización en la que la edad toma un papel relevante.

Las zonas de cruising son espacios de "ligoteo" de baja exigencia, en la medida en que no es necesario arreglarse, invitar a nadie a una copa, ni requieren de una inversión económica para la satisfacción de los deseos sexuales con desconocidos. El tipo de ropa de los usuarios, a diferencia de otras zonas para la interacción sexual, como bares o discotecas, no suele ser objeto de interés para el resto de participantes. Las personas acostumbran a ir con ropa de calle, sin arreglar o incluso con la ropa de trabajo. Rara vez se puede observar a personas que van a las zonas de cruising con prendas de fiesta, solamente en el caso de que no hayan podido ligar en la discoteca y se presenten en la zona de cruising como último recurso; este es el caso de la playa de Sitges, en el que los participantes acuden a la zona de cruising una vez 
los bares han cerrado. En ocasiones, se presentan algunos participantes con ropa deportiva: mallas, camiseta de running o zapatillas de atletismo. Este hecho lleva a pensar que se trata de personas que utilizan el deporte como un elemento de ocultamiento de los intereses reales de visitar el parque de Montjuïc.

\section{MARICAS, GAIS Y HETEROSEXUALES: EL CONFLICTO DE LA IDENTIDAD EN LAS ZONAS DE CRUISING}

"No digas eso, que suena muy mal", me reprendió Julián, un participante de la zona de cruising de Gavà cuando le dije: "soy un maricón que te quiere entrevistar". El señor, de unos sesenta y pico años, se sintió profundamente ofendido y me corrigió diciendo que yo no era maricón, que así nos llamaban antes, cuando estaba mal visto, que lo que debía decir es que era gay. La discusión terminológica pareció importarle mucho más que el hecho de encontrarse con un antropólogo interesado en entrevistarle a media noche. Durante cinco minutos, defendió la necesidad de un uso apropiado del lenguaje que no generara más estigma sobre nosotros, "los gais". No pude hacer otra cosa que pedir disculpas y seguir la entrevista con el máximo cuidado de no ofender. Sin embargo, su respuesta me hizo pensar en la cuestión de la identidad del sujeto como punto de partida para analizar los conflictos que se generan en torno a esta asignación identitaria a partir del acto sexual. En este sentido, uno de los participantes, también de Gavà, aseguraba que:

Aquí estamos el cincuenta por ciento maricones y cincuenta por ciento casados. Por las mañanas suelen venir más casados a pegar un polvo rápido. Y lo que también hay es mucho yayo. Por la mañana esto está lleno de viejos (Toño, 41 años).

La cuestión es que es difícil saber quiénes se identifican como gais, bisexuales o heterosexuales en un espacio en el que apenas se habla y en el que el interés por el anonimato es uno de los principios de la organización. De hecho, construir su identidad a partir de la práctica sexual es una cuestión menor para aquellos que no han salido del armario o que se declaran heterosexuales en las zonas de cruising. Por otra parte, quienes se autodenominan gais acostumbran a tener menos conflictos con la identidad sexual y sienten que, de alguna manera, han "evolucionado" con respecto a sus compañeros del parque que no se reconocen como homosexuales. Se presentan, en comparación con los que se consideran heterosexuales, o que están dentro del armario, como si fuesen un paso por delante, los ridiculizan por la incoherencia entre sus acciones y su identidad. Uno de mis informantes manifestaba:

Aquí viene gente que dice "estoy aquí porque he venido"; "hazme lo que quieras pero yo no hago nada". Estos son normalmente la gente casada que no se consideran gais, porque ellos no meten mano. Pero tanto es el que mete como el que se deja meter [...] No se creen gais pero lo son tanto como yo, porque el que se mete en un rincón con un tío o en una cama con otro tío es porque le va el rollo. ¿O no? (Julián, 64 años).

Una persona que está en la zona de cruising y que se considera gay y mantiene relaciones sexuales con otros hombres, no genera ningún conflicto consigo mismo entorno a su identidad sexual, se presenta coherente entre su identidad y su práctica sexual. Al fin y al cabo, está en el parque para follar con otros hombres, que es lo 
mismo que hacen los gais en las saunas, discotecas, chats, etc. El problema lo encontramos cuando no existe esta correlación entre identidad y práctica, es decir, cuando podemos descubrir la contradicción en el sujeto que, a pesar de participar del gozo sexual con otros hombres, no se considera homosexual. Estos participantes se encuentran ante un conflicto que en un juicio social no llevaría a ningún equívoco: son hombres que mantienen relaciones sexuales con hombres y, por lo tanto, se trata indiscutiblemente de homosexuales. ¿Por qué se niegan a aceptar lo que la sociedad les dice que son? Existen, al menos, dos razones para responder a esta pregunta. La primera de ellas pasaría por el principio homofóbico que genera estigma y rechazo hacia quienes mantienen relaciones sexuales con personas de su mismo sexo. El hecho de ser homosexual es entendido como un elemento que pertenece al ámbito de lo privado y que en él debe mantenerse para evitar las consecuencias del estigma. Pasar a formar parte del grupo de los indeseables tiene consecuencias que el sujeto conoce o al menos puede predecir (Eribon 2004).

Por otro lado, el estigma supone una pérdida inmediata de los privilegios de pertenecer al grupo de los "normales" (Goffman 2003). Y he aquí la segunda razón: los hombres que se presentan como heterosexuales disponen de una serie de privilegios sociales que tienen que ver fundamentalmente con el acceso al poder y a los recursos en tanto que heterosexuales (Bourdieu 2005; Wittig 2006). "Ningún hombre heterosexual que se encuentre con un homosexual deja de sentirse amenazado" asegura Henning Bech (1997:41). Pero, ¿̇cuál es la amenaza? El desafío ante el sujeto homosexual no es un temor de agresión o violación, como se ha pretendido argumentar a partir de los discursos sobre el pánico gay (Sedgwick 1998). La verdadera amenaza es la de verse convertido en uno de ellos, la de perder los privilegios que ofrece la categoría hombre heterosexual. El amargor está en la posibilidad de sentirse atraído por aquello que debería repugnar. El homosexual es un personaje útil que permite ser negado por ausencia de virilidad y por la traición a la sexualidad del hombre verdadero (Guasch 1991). La homosexualidad masculina se construye así alrededor de la idea de la feminización. E inequívocamente, "la peor humillación para un hombre es verse convertido en mujer" (Bourdieu 2005: 36).

Si aceptamos estos dos argumentos como válidos, también deberíamos preguntarnos acerca de las maniobras necesarias para permanecer en ese lugar conflictivo entre hombres que se declaran como heterosexuales, pero que mantienen relaciones sexuales con otros hombres. En este caso, propongo analizar dos estrategias fundamentales que se llevan a cabo en las zonas de cruising. Una primera pasa por el recurso del anonimato, a partir del cual se resolvería el primero de los argumentos relativos al estigma y la evitación pública de la condición de homosexual. La segunda estrategia está relacionada con la masculinización del participante de las zonas de cruising, es decir, la presentación de un sujeto altamente masculinizado que, aunque mantenga relaciones sexuales con otros hombres, no está en disposición de perder los privilegios de la sociedad heterosexista y mucho menos de aceptar estar en el lugar alterno; el de homosexual5. "Yo vengo a dar biberón" decía Ricardo, uno de los par-

\footnotetext{
${ }^{5}$ En este sentido, es interesante aproximarse a la propuesta de Connell y Messerchmidt (2005) que discuten la existencia de una única masculinidad y afirman que existen diferentes masculinidades hegemónicas en las que se entrelazan diversos patrones que contribuyen al mantenimiento de una hegemonía externa.
} 
ticipantes de 43 años de la zona de cruising de Montjuïc para no poner en cuestión su práctica y su identidad. Los hombres que se consideran heterosexuales en las zonas de cruising formulan una nueva elección discursiva a partir de su inventario cultural del comportamiento masculino que no pone en duda su verdadera masculinidad; es decir, de alguna manera se reconstruye una nueva masculinidad que permita conciliar el hecho de ser un hombre que está teniendo sexo con otros hombres (Enguix 2012).

La masculinidad de los participantes de las zonas de cruising es una masculinidad quebrada que viene determinada precisamente por la violación de esta norma principal de la organización sexual: la heterosexualidad. De manera que, aunque se estén llevando a cabo prácticas sexuales con otros hombres, algunos usuarios no ponen en duda su masculinidad a partir de la confirmación de una heterosexualidad discursiva o corporalizada. Es decir, el sujeto se presenta abiertamente como heterosexual, reivindica su heterosexualidad en el espacio de cruising, para evitar poder ser confundido con los "otros" homosexuales que, por el contrario, sí que van a las zonas de ligue porque se sienten atraídos por otros hombres. La reivindicación de la heterosexualidad discursiva parte de la percepción de la práctica sexual con otros hombres como un hecho aislado, particular y transitorio que nada tiene que ver con los impulsos "naturales" del sujeto, sino que se trata de una actividad excepcional a la que ha llegado a causa de algunas circunstancias puntuales. El discurso se articula a partir de la satisfacción de las necesidades incontrolables del hombre, el cual se presenta como un sujeto que debe atender a sus impulsos sexuales que se encuentran fuera de control. El hombre heterosexual que frecuenta las zonas de cruising considera que restablecerá su condición "natural" cuando tenga acceso nuevamente al sexo con mujeres.

También pueden existir otras reivindicaciones a partir de lo que he llamado heterosexualidad corporalizada. Se trata de ejercicios de masculinización a partir de una determinada presencia social del cuerpo. El hecho de que en las zonas de cruising la ausencia de lenguaje verbal sea un principio de interacción no impide que, a través del cuerpo, los participantes puedan expresar deseos y ciertos rasgos de identidad. Para ello, algunos participantes asumen roles sexuales siempre activos y dominantes, otros reducen su participación al voyeurismo para no tocar los genitales de otros hombres. Caminan firmemente, con las piernas ligeramente abiertas, el pecho fuera, una mirada penetrante, evitando cualquier signo que se pueda relacionar con la "pluma" gay. Muestran desinterés por los cuidados y el gozo de la pareja sexual, ya que la cuestión del cuidado está altamente feminizada.

Los participantes heterosexuales, o que "parecen" heterosexuales, son los más buscados como pareja sexual. Representan una masculinidad que resulta muy atractiva para una buena parte de los usuarios. Pero, sin embargo, no todos los usuarios se encuentran en disposición de representarlo. Para ser heterosexual o parecerlo, en las zonas de cruising es necesaria una presencia corpulenta y unos rasgos físicos muy determinantes de lo masculino. En definitiva, es necesario disponer de los atributos más significativos que la sociedad ha designado para la categoría hombre. En este sentido resulta revelador el trabajo de Lores (2012) en tanto que demuestra que el capital corporal está dotado de una gran carga simbólica que determina las posibilidades de acceso a la negociación sexual. 
No todos los hombres son corpulentos, fuertes, con vello corporal, etc. En otros escenarios sociales, podrían recurrir al lenguaje verbal, a la presentación de su esposa e hijos, a conversaciones machistas y homófobas que dieran cuenta de su condición heterosexual, pero en el contexto del cruising estos recursos no pueden ser utilizados, ya que las interacciones se realizan a partir del principio del silencio (Langarita 2013). Es por ello por lo que algunos participantes casados o públicamente heterosexuales asumen su carácter homosexual de manera temporal y transitoria mientras están en las zonas de cruising, pero fuera de ellas prefieren mantener un discurso, una práctica y una presencia corporal acorde con la lógica heterosexual. Es decir, se dividen entre una presencia pública heterosexual y una existencia que nadie dudaría en catalogar como homosexual (Hubbard 2001).

Hay algunos hombres que no representan ese modelo de masculinidad basado en la heterosexualidad como principio rector, pero a los que tampoco clasificaríamos como gais si atendiéramos exclusivamente al modelo que se ofrece desde la subcultura de consumo gay dominante. No se trata de hombres jóvenes, ni tampoco de personas con cuerpos especialmente trabajados en el gimnasio, no son muchachos que se arreglan para ir a la zona de cruising, ni aceptan una relación afectiva con otros hombres. Están allí para disfrutar, sin definirse sexualmente, pero disfrutando de lo que hacen, alternando sus roles sexuales y participando de la subcultura del parque.

Desde los programas y discursos para la prevención de enfermedades de transmisión sexual se ha pretendido salvar este conflicto de identidad y representación con la noción de hombres que tienen sexo con hombres (HSH). Se trata de un intento de incluir a aquellas personas que se identifican como heterosexuales, o aquellas personas que no se consideran gais pero que también tiene relaciones sexuales con otros hombres, y así poder dirigir las campañas preventivas de la enfermedad a un sector más amplio de la población. Sin embargo, este término resulta problemático si intentamos extrapolarlo a otros contextos fuera del ámbito de la salud. La noción de HSH neutraliza y aísla las prácticas sexuales de la realidad cultural, como si el sexo fuese un acto corporal carente de significados sociales. Cuando dos personas del mismo sexo mantienen relaciones sexuales, no se trata de un hecho inocente, aislado y normalizado. El término HSH se sitúa en un contexto ficticio, en el que no existen relaciones de poder entre los distintos grupos sociales, y donde tanto unas prácticas sexuales como otras están igualmente legitimadas por un imaginado consenso social basado en el principio de igualdad. Por ello, trasladar la noción de HSH a un estudio de estas características genera algunos problemas de análisis que difícilmente se pueden soslayar.

Un lugar excepcional tendrían las personas bisexuales, a las que algunos practicantes no saben dónde ubicar en la relación entre práctica sexual e identidad. En la cita que se presenta a continuación se puede verificar esta confusión en una discusión entre dos participantes:

PD - Vienen bisexuales que solo quieren que se la comas y ya está.

Toño - Un bisexual no es eso. ¿Un bisexual solo quiere que se la coman? No.

PD - Pues entonces, ¿qué es un bisexual?

Toño - Pues que le gustan los hombres y las mujeres. Montárselo tanto con un tío como con una tía. Pero no solo que se la chupen. Hay bisexuales que follan tíos. Así que tú no sabes ni lo que eres. Dices que los bisexuales son los que solo quieren que se la 
chupen y no es así. Los bisexuales son la carne y el pescado. Un tío que le gusten los tíos y las tías. Lo mismo folla a un tío que a una tía. ¿Chupársela? Pues a todo el mundo le gusta que se la chupen. ¿A quién no?

(Toño y participante desconocido - PD).

Podemos ver una vez más la necesidad de coherencia entre práctica sexual e identidad sexual. No estar en ninguno de los polos sexuales provoca una cierta dificultad de clasificación que los participantes ponen en entredicho.

Por otro lado, es necesario puntualizar que la figura femenina es cosificada por algunos participantes de las zonas de cruising. De alguna manera, parece que la mujer con la que se casaron, o las mujeres a las que deberían tener como objeto de deseo, fuesen las responsables de la opresión personal que sienten por desear a personas de su mismo sexo. En este sentido, un participante de la zona de cruising de Montjuïc aseguraba:

No soporto a mi mujer que siempre quiere saber dónde estoy, tengo que apagar el móvil para que no me llame y me caliente la cabeza. [...] Lo que hago por las mañanas es follarla bien, le doy candela para dejarla tranquila y relajada todo el día. Porque un hombre que es hombre de verdad sabe hacer gozar a una mujer. Vosotros los gais no sabéis distinguir cuando una mujer goza de verdad. La mujer que jadea y chilla, esa no goza, esa está fingiendo. La que goza es la que se queda callada mientras el hombre la va follando [...] Yo lo que querría es divorciarme y que alguno se la monte y que le dé toda la candela que quiera para dejarla contenta (Ricardo, 43 años).

Este tipo de comentarios presenta a la mujer como un sujeto pasivo "al que dar candela", objeto de intercambio y sin valor. Se trata de un discurso inequívocamente misógino que no se ve reñido con una práctica sexual "desviada", sino que, por el contrario, la refuerza. Sitúa a la mujer en un lugar ajeno en el que, aunque no se presente como objeto de deseo, permite no poner en cuestión la masculinidad del emisor. Es decir, aunque se trata de un hombre que desea mantener relaciones sexuales con otros hombres, este discurso le ayuda a construir una cierta coherencia entre su práctica sexual y su identidad a partir de la relación de sometimiento que establece con la mujer.

Existen otras referencias a la mujer por algunos usuarios que apelan a la existencia de una novia o mujer para aumentar su grado de legitimidad y aclarar que su presencia en la zona de cruising es circunstancial. Así, por ejemplo, en una ocasión un joven informante me decía que le había depilado la polla su novia mientras hacían el amor. En este caso, el muchacho hizo diversas referencias al sexo femenino figurando que lo que estábamos haciendo entre nosotros fuese una especie de sustituto de aquello que hace con su novia: "la pongo entre tus piernas como si fuera un chochito", me decía. Así, la mujer toma presencia a través de la feminización del otro, lo que permite mantener el estatus masculino de quien enuncia este discurso.

\section{LAS RELACIONES SEXO-AFECTIVAS}

La actividad del cruising se presenta como sexo rápido, fácil y sin obligaciones. Sin embargo, para una buena parte de los usuarios, este tipo de relaciones no son cualitativamente mejor que las que se producen en el marco de la pareja, sino que 
se trata de un sexo más conveniente (Weingberg y Williams 1975: 125). Es indiscutible que algunos participantes de las zonas de cruising van allí por morbo y facilidad de acceso al sexo; pero otros reconocen que prefieren otras formas de sexo, aunque dadas sus circunstancias no pueden acceder a ellas. Tal y como he podido verificar en las conversaciones mantenidas a lo largo del trabajo de campo, muchos de los participantes aseguran que no asistirían a las zonas de cruising si se encontrasen en otra situación como la que supondría tener pareja, dinero para participar del circuito comercial gay o vivir fuera del armario. Casi ningún informante se siente orgulloso de lo que hace en las zonas de cruising; están allí, fundamentalmente, hasta que se produzca algún cambio que les permita encontrar otras vías de acceso al sexo.

Así, al igual que en la sociedad madre, la idea de pareja estable invade el imaginario de buena parte de los participantes, que proyectan su futuro al lado de una pareja con la que ser felices y buscar la aceptación social (ver Esteban 2011). Sin embargo, muchos no pueden hacerlo porque están dentro del armario, su comunidad no lo aceptaría o porque son objeto de rechazo social por el conjunto de la población.

A pesar de este deseo de pareja, son pocos los que se aventuran a buscarla en las zonas de cruising. Este tipo de espacios no son vistos como lugares en los que encontrar un buen novio. Los usuarios no van a las zonas de cruising a conocer gente, sino que van a follar. Aunque la idea de pareja está presente, el lugar donde buscarla sería otro. "A mí me gustan los chicos, pero no como los que vienen aquí decía un participante anónimo en Montjuïc. Pero, además, en este caso, continuaba manifestando que desearía tener un novio que no conociese las zonas de cruising, ya que quería cumplir con el principio de fidelidad y los hombres que van a las zonas de cruising no acostumbran a ser fieles. Otro participante afirma que:

Esto es sexo puro y duro. Porque quien espere encontrar aquí su príncipe azul, no lo va a encontrar. ¿Cómo no sea por casualidad? A ver, dejemos un dos por ciento a la casualidad. Por aquí la mayoría viene al aquí te pillo y aquí te mato. Y adiós (Julian, 64 años).

El reconocimiento de la pareja como el mejor espacio para el sexo es una idea compartida por una buena parte de los usuarios, aunque no por todos. Los discursos sobre la fidelidad son muy variados. Algunos de los participantes consideran que la fidelidad es un valor absoluto y necesario para el funcionamiento correcto de una relación en pareja. Sin embargo, otros son más flexibles y creen que la relación abierta es la más idónea para las parejas homosexuales.

Entre dos tíos lo mejor es la pareja abierta. Ser liberales. En la cama haces el amor con tu pareja pero luego haces escapadas para pegar un polvo. Aquí se folla y con tu pareja haces el amor. ¡Qué es bien distinto! Aquí se viene a follar, no a hacer el amor. Se viene a desahogarse, no a dar cariño a nadie (Toño, 41 años).

La separación entre sexo y amor es habitual para una buena parte de la población homosexual, que reconoce que puede ir unido pero que no necesariamente tiene que ser así. Por lo tanto, el hecho de tener pareja no siempre es un obstáculo para poder visitar las zonas de cruising. Para algunos es una necesidad ante la falta de sexo con la pareja: 
Yo tengo mi pareja desde hace muchos años, ahora ya estamos casados y todo, pero él tiene que tomar una medicación y la cosa ya no le funciona. Entonces yo tengo que hacer algo, ¿no? También me tengo que desahogar, por eso vengo aquí, a echar la cañita (Julián, 64 años).

En las zonas de cruising, todos los usuarios consideran que lo que se va a hacer allí es una actividad sexual sin amor, en la cual el objetivo fundamental es satisfacer los deseos. Y aunque algunos participantes reconocen que existen otros escenarios sociales para un sexo más satisfactorio, son numerosos los relatos sobre sexo placentero en las zonas de cruising. Es decir, a pesar de que las zonas de cruising son percibidas como lugares poco adecuados para el sexo, algunos participantes encuentran en ellas experiencias satisfactorias que permanecen en su recuerdo. "He tenido abrazos preciosos en la zona de cruising. Yo flipo con eso, a veces me fascina" (Guillermo, 35 años, mexicano residente en Barcelona). Las zonas de cruising permiten construir narrativas del placer que perduran en la memoria de quienes han disfrutado de la experiencia. Michael Celse (1995: 243) admite que se trata de la única vía de escape para muchas personas homosexuales que son incapaces de aceptar su deseo y afecto por otros hombres. Para el autor, se trata de una actividad que opera bajo la distinción entre los sentimientos y el sexo, convirtiendo así al compañero sexual en un sujeto indiferente, un instrumento que da placer sin más. Por su parte, Michael Pollak piensa que podría tratarse de un sexo basado en el intercambio de placeres, donde los usuarios tienen algo que ofrecer y algo que buscar, un "trueque de orgasmo por orgasmo" (Pollak 1987: 77). No obstante, este modo de interacción puede hacer que la relación opere bajo un modelo utilitarista, ya que no existe ningún motivo parar ser leal a la pareja sexual cuando los participantes ya han alcanzado el orgasmo. Uno de los participantes en esta investigación explica:

Muchas personas se van cuando se corren. Pero yo normalmente no me voy. Me suelo esperar a que la otra persona se corra. No me voy y le digo — ¡Venga acábatelo tú solo! Pero tampoco voy a hacer ningún esfuerzo. ¿Sabes? Y si no me gusta o lo estoy pasando mal, lo dejo. Puedo acabar dejándolo sin problemas (Albert, 32 años).

La reciprocidad en la relación sexual anónima, como en el resto de relaciones sexuales, es un elemento fundamental para el acceso al gozo. Sin embargo, en las zonas de cruising, se trata de una reciprocidad que concierne únicamente al ámbito sexual y que se delimita al tiempo que dura el encuentro, sin extenderse a otros ámbitos de la vida social. No son relaciones que podrían buscar recompensas en otros ámbitos sociales, como se da en las relaciones de pareja, en las que el sexo es una vía de acceso a otros recursos económicos y sociales, por ejemplo. En tanto que los participantes no esperan ningún beneficio futuro, no adquieren ninguna deuda tras la interacción sexual, y, por lo tanto, se puede abandonar ésta sin que ello provoque una ruptura en el acuerdo.

\section{CONCLUSIONES: HACIA LA COMUNIDAD DE PRÁCTICA}

No es posible construir un perfil de usuario claro, definido y estable de zonas de cruising porque existen diversos factores que se sobreponen los unos a los otros y 
que combinados pueden dar lugar a un sin fin de resultados. Es mucho más sugerente tomar la idea de comunidad de práctica para referirnos al conjunto de personas que participan en la zona de cruising. Esta noción fue creada por Etienne Wenger (1998) como un instrumento vinculado al aprendizaje compartido, pero ha sido extendida a diversos análisis en ciencias sociales y nos puede servir para acotar a los practicantes del cruising.

Wenger considera que una comunidad de práctica es un conjunto de personas que comparten unos intereses similares y unas competencias comunes, que distinguen a los miembros de la comunidad de otras personas. Apunta que para formar parte, no es necesario únicamente tener intereses en común, sino que también se debe interactuar con los otros miembros para el aprendizaje. Los usuarios de las zonas de cruising son participantes de una comunidad en la que se desarrollan un repertorio de recursos y herramientas para conducir a la interacción sexual con otros hombres desconocidos. Al fin y al cabo, lo que les une a todos es una práctica basada en un mismo interés. En las zonas de cruising, los participantes son una comunidad en la medida en que comparten un espacio, unos intereses y una práctica con sus respectivas normas asociadas. Cabe destacar, eso sí, que los practicantes no tienen ningún interés en continuar con el vínculo después de concluir con el objetivo final, por lo tanto no se trata de una comunidad con identidad propia, sino más bien una comunidad de la que el sujeto forma parte mientras se encuentra en la zona de cruising. La práctica del cruising se enseña y se aprende. Cualquier nuevo participante necesita conocer el lenguaje y los canales de comunicación que ordena las zonas de cruising; a las pocas visitas ya ha aprendido las formas de interacción que se dan en estas zonas y su importancia para garantizar el anonimato de los participantes.

Las zonas de cruising demuestran que a pesar de compartir un mismo espacio social con la llamada "comunidad homosexual", no necesariamente se produce una solidaridad política. Es perfectamente posible la coexistencia de racismo, estratificación social y sesgo de clase con el deseo sexual. Es necesario, por lo tanto, preguntarnos si al hablar de comunidad gay como categoría y como realidad social estamos invisivilizando los procesos de construcción de hegemonía y subalternidad que se dan entre los hombres que desean a otros hombres (Villaamil y Jociles 2008). Se puede ser gay y racista a la vez, la comunidad homosexual también conforma algunos ejercicios de exclusión, al igual que la sociedad madre, que segregan y diferencian los cuerpos deseables de los que no lo son.

Cualquier asignación identitaria a partir de una única práctica sexual resultará problemática en la medida en que no tenga en cuenta otros valores que se entremezclan con su propia existencia como el valor etnia, edad, y clase social. La comunidad gay no existe, al menos en singular, no existe una comunidad gay capaz de superar su relación con el medio económico y social. La noción de comunidad gay de ninguna manera puede ser considerada como un valor neutro, que reúne sin conflicto a todos aquellos hombres que desean a otros hombres. Aunque la idea de comunidad gay se presenta como superadora de otras diferencias, una vez contrastadas, rápidamente salen a la luz y sitúan a cada sujeto en el lugar que le corresponde, en función de los mismos criterios de clase, raza, género y edad que funcionan en la sociedad madre. 


\section{BIBLIOGRAFÍA CITADA}

Aramburu Otazu, M. 2002. Los otros y nosotros. Imágenes del inmigrante en Ciutat Vella de Barcelona. Madrid: Ministerio de Educación, Cultura y Deporte.

Bauman, Z. 2003. Trabajo, consumismo y nuevos pobres. Barcelona: Gedisa.

Bech, H. 1997. When Men Meet. Cambridge: The University of Chicago Press.

Beck, U. 2006. La sociedad del riesgo. Hacia una nueva modernidad. Barcelona: Paidós.

Binnie, J. 2011. "Class, Sexuality and Space: a Comment". Sexualities 14 (1): 21-26.

Bourdieu, P. 2005. La dominación masculina. Barcelona: Anagrama.

Brettell, C. 2003. Anthropology and Migration. Essays on Transnatonalism, Ethnicity and Identity. Oxford: Altamira Press.

Castel, R. 1997. La metamorfosis de la cuestión social. Barcelona: Paidoìs.

Celse, M. 1995. "Sida: luchar contra la homofobia", en Llamas, R. (comp.), Construyendo sidentidades. Estudios en el corazón de una pandemia: 233- 247. Madrid: Siglo XXI.

Connell, R. V. y Messerchmidt, J. W. 2005. "Hegemonic Masculinity. Rethinking the Concept". Gender and Society 19 (6): 829-859.

Delgado, M. 2011. El espacio público como ideología. Madrid: Catarata.

Duberman, M. 1994. Stonewall. Nueva York: Penguin Books.

Enguix, B. 2012. "Cultivando cuerpos, modelando masculinidades". Revista de Dialectología y Tradiciones Populares 67 (1): 147-180.

Eribon, D. 2004. Una moral de lo minoritario. Variaciones sobre un tema de Jean Genet. Barcelona: Anagrama.

Esteban, M. L. 2011. Crítica del pensamiento amoroso. Barcelona: Bellaterra.

Flowers, P.; Hart, G. y Marriott, C. 1999. "Constructing Sexual Health. Gay Men and 'Risk' in the Context of a Public Sex Environment”. Journal of Health Psychology 4 (4): 483- 495.

Fraser, M. 1999. "Classing Queer: Politics in Competition". Theory, Culture and Society 16 (2): 107-131.

Goffman, E. 2003. Estigma. La identidad deteriorada. Madrid: Amorrortu.

Green, A. I. 2008. "The Social Organization of Desire: the Sexual Fields Approach". Sociological Theory 26 (1): 25-50.

Guasch, O. 1991. La sociedad rosa. Barcelona: Anagrama.

Heaphy, B. 2011. "Gay Identities and the Culture of Class". Sexualities 14 (1): 42-62.

Hennessy, R. M. 2000. Profit and Pleasure. Sexual Identities in Late Capitalism. Londres y Nueva York: Routledge.

Hubbard, P. 2001. "Sex Zones: Intimacy Citizenship and Public Space». Sexualities 4 (1): 51-71.

Humphreys, L. 1975. Tearoom Trade. Impersonal Sex in Public Places. Nueva York: Enlarged.

Johnson, P. 2008. "Rude Boys: the Homosexual Eroticization of Class". Sociology 42 (1): 65-82.

Langarita, J. A. 2013. “Sexo sin palabras. La función del silencio en el intercambio sexual anónimo entre hombres". Revista de Antropología Social 22: 313-333

Lauman, E. O.; Gagnon, J. H.; Michale, R. T. y Michaels, S. 1994. The Social Organization of Sexuality. Londres: The University of Chicago Press. 
Lores, F. 2012. Deseo y peligro: anotaciones antropológicas a una teoría de la contaminación y de los cuidados sexuales. Tesis Doctoral. Madrid: Universidad Complutense de Madrid.

Pollak, M. 1987. "La homosexualidad masculina o: ¿la felicidad en el gueto?», en Aries, P.; Beinjin, A.; M. Foucault, M., et.al. (eds.), Sexualidades occidentales: 71-102 Barcelona: Paidós.

Reece, M. y Dodge, B. 2004. "Exploring the physical mental and social well-being of gay and bisexual men who cruise for sex on a college campus". Journal of Homosexuality 46 (1): 111-136.

San Román, T. 1990. Vejez y cultura. Hacia los límites del sistema. Barcelona: Fundación La Caixa.

Santamaría, E. 2002. La incógnita del extraño. Una aproximación a la significación sociológica de la "inmigración no comunitaria". Barcelona: Anthropos.

Schacht, S. P. (ed.). 2004. "Special issue". International Journal of Sociology and Social Policy 24 (3-4-5).

Sedgwick, E. K. 1998. Epistemología del armario. Barcelona: Ediciones de la Tempestad.

Taylor, Y. 2011. "Sexualities and Class". Sexualities 4 (1): 3-11.

Villaamil Pérez, F. y Jociles Rubio M. I. 2008. "Diferencias y desigualdades entre los HSH usuarios de locales comerciales de encuentro sexual: algunas contribuciones a las estrategias comunitarias de prevención del VIH". Etnográfica 12 (2): 185-321.

Wenger, E. 1998. Communities of Practice: Learning, Meaning, and Identity. Cambridge: Cambridge University Press.

Weingberg, M y Williams, C. J. 1975. "Gay Bath and the Social Organization of Impersonal Sex". Social Problems 23 (2): 124-136.

Wittig, M. 2006. El pensamiento heterosexual y otros ensayos. Madrid y Barcelona: Egales. 